\title{
Caffeic Acid Inhibits the Uptake of 2-Amino-1-methyl-6-phenylimidazo- $[4,5-b]$ pyridine (PhIP) by Inducing the Efflux Transporters Expression in Caco-2 Cells
}

\author{
Yun-Jin Hong," Sung-Yong Yang," Mi-Hyun Nam, Yun-chang Koo, and Kwang-Won Lee* \\ Department of Food Bioscience and Technology, College of Life Sciences and Biotechnology, Korea University; Seoul \\ 136-701, Republic of Korea. \\ Received July 7, 2014; accepted October 30, 2014; advance publication released online November 15, 2014
}

\begin{abstract}
2-Amino-1-methyl-6-phenylimidazo[4,5-b]pyridine (PhIP) is formed as a by-product of the Maillard reaction during cooking and frying of protein-rich foods at high temperatures. PhIP is metabolized in the liver by cytochrome P450 1A1/2 to carcinogenic metabolite $N$-hydroxy PhIP, which can form DNA adduct. The ATP binding cassette (ABC) transporters, P-glycoprotein (P-gp), multidrug resistance-associated protein 2 (MRP2) and breast cancer resistance protein (BCRP) are capable of transporting the food-borne procarcinogen PhIP back to the intestinal lumen. In the present study, the uptake and efflux of PhIP were assessed by determining apparent bidirectional permeability coefficients and efflux ratio. The efflux ratio of PhIP with $10 \mu \mathrm{M}$ caffeic acid was significantly increased compared with control. The mRNA levels of efflux transporters were measured to evaluate the effect of caffeic acid in the presence of PhIP on efflux-mediated transport of PhIP. Caco-2 cells exposed to $10 \mu \mathrm{M}$ caffeic acid for 3 and $6 \mathrm{~h}$ also exhibited higher mRNA levels of P-gp and BCRP than those of control. In contrast, the mRNA level of MRP2 was only slightly induced after $3 \mathrm{~h}$ and $6 \mathrm{~h}$. Therefore, caffeic acid at low concentration is expected to be used not only as an antioxidant, but also as an inhibitor of the absorption of food borne carcinogen heterocyclic amines. However, further studies, especially in vivo studies, are required to confirm these results.
\end{abstract}

Key words ATP binding cassette transporter; breast cancer resistance protein; caffeic acid; multidrug resistance-associated protein; P-glycoprotein; 2-amino-1-methyl-6-phenylimidazo[4,5-b]pyridine

The heterocyclic aromatic amines (HAAs) are formed during the cooking process of various meat in the presence of mixtures of amino acids, carbohydrate and creatine, or creatinine. ${ }^{1)}$ Studies have shown that human exposure to the HAAs in food was estimated to be $0.1-10 \mu \mathrm{g} \mathrm{HAAs} / \mathrm{d} /$ person. $^{2)}$ The most abundant HAAs is 2-amino-1-methyl6-henylimidazo[4,5-b]pyridine (PhIP), which can also occurs in mainstream smoke at levels up to $23 \mathrm{ng} /$ cigarette, and has also been identified in incineration ash and in airborne and diesel-exhaust particles. ${ }^{3,4)} \mathrm{PhIP}$ is biotranformed in the liver by cytochromes P450 1A1 and 1A2 to its carcinogenic metabolite $N$-hydroxy PhIP. ${ }^{5)}$ The $N$-hydroxy-PhIP can directly bind to DNA or be metabolized by phase II enzymes to form unstable esters which produce nitrenium ion that can bind DNA base. ${ }^{6,7)}$ It may be also reduced to the parent compound by reacting with glutathione (GSH) or catalyzed by glutathione- $S$ transferase (GST) ${ }^{8)}$ These reactions are associated with a high risk of colorectal, breast, pancreatic, and prostate cancers. ${ }^{9-11)}$

The excretion of food ingredients or toxic compounds can depend largely on active transporter like ATP binding cassette (ABC) efflux transporters including P-glycoprotein (P-gp; ABCB1), multidrug resistance-associated protein 2 (MRP2) $(\mathrm{ABCC} 2)$, and breast cancer resistance protein (BCRP) (ABCG2) that are localized in the apical membrane of the enterocyte. These efflux transporters are involved in catalyzing the efflux of compounds to the intestinal luminal side, resulting in reduced bioavailability. On the other hand, MRP1 (ABCC1), MRP3 (ABCC3) and MRP5 (ABCC5) localized in the basolateral membrane facilitate the uptake of compounds

\footnotetext{
\# These authors contributed equally to this work.

* To whom correspondence should be addressed. e-mail: kwangwon@korea.ac.kr
}

into the serosal side resulting in increased bioavailability. ${ }^{12,13)}$ The involvement of ABC transporters in the excretion of $\mathrm{PhIP}$ has been demonstrated using Caco-2 monolayers, Mrp2-deficient $\mathrm{TR}^{-}$rats, and perfused human placenta. Pre-incubation with inhibitors of P-gp and MRP2 inhibited the efflux transport of PhIP. In Mrp2-deficient $\mathrm{TR}^{-}$rats, total excretion of $\mathrm{PhIP}$ and its metabolites in bile was reduced compared with Wistar rats. ${ }^{14)}$ The specific BCRP inhibitor also increased the transfer of ${ }^{14} \mathrm{C}$-PhIP from maternal to fetal circulation. ${ }^{15,16)}$

The antioxidant activities of phenolic compounds usually found in foods have been investigated. Our previous studies showed that caffeic acid extracted from perilla leaves has not only antioxidant activity, and provides protection from hepatotoxicity in tert-butyl hydroperoxide ( $t$-BHP)-treated SpragueDawley (SD) rats. ${ }^{17,18)}$ While previous study reported that caffeic acid was mainly transported via paracellular diffusion, its metabolites, $m$-coumaric acid and 3-( $m$-hydroxyphenyl)propionic acid, produced by colonic microflora were absorbed by the monocarboxylic acid transporter (MCT). ${ }^{19)}$ Hydroxycinnamic acids including caffeic acid which are administered as free acids, they are extensively metabolized by phase II enzymes to transform into sulfated and/or glucuronidated conjugates as the predominant forms in plasma. ${ }^{20)}$ In their study, caffeic acid showed significant inhibition $\left(\mathrm{IC}_{50}, 5.22 \mu \mathrm{M}\right)$ of an endogenous compound, $p$-amnihippuric acid transport by organic anion transporterl (OAT1). However, the role of caffeic acid on the efflux of compounds via $\mathrm{ABC}$ transporters has not been widely investigated.

In the present study, we focused on the most pharmacologically relevant $\mathrm{ABC}$ efflux transporters (P-gp, MRP2 and BCRP), and investigated the effect of caffeic acid on 
the transport of PhIP through the human intestinal epithelial Caco-2 cell monolayers. The apparent permeability coefficients estimated in both directions provided interaction between PhIP and caffeic acid, and mRNA levels of efflux transporters clarified the efflux mechanism.

\section{MATERIALS AND METHODS}

Cell Culture The human colon carcinoma cell line Caco-2 cells were purchased from American Type Culture Collection (ATCC, Rockville, MD, U.S.A.). The cell line was grown in a humidified incubator containing $5 \% \mathrm{CO}_{2}$ and $95 \%$ air at $37^{\circ} \mathrm{C}$. The growth medium of Caco-2 cell was minimum essential medium (MEM) from GIBCO (Grand Island, NY, U.S.A.) containing $0.9 \mathrm{~mm}$ pyruvic acid, supplemented with 10\% fetal bovine serum (FBS). Cell cultures were split $1: 3$ when 70-90\% confluent, using trypsin/ethylenediaminetetraacetic acid (EDTA). Cells at passages 23 to 28 were used for the transport experiments. The culture medium was changed every other day.

Bacterial Reverse Mutation Assay The test substance was used at two different doses of PhIP (50 and $450 \mu \mathrm{M}$ per plate) and two different dose of caffeic acid ( 1 and $10 \mu \mathrm{M}$ per plate) in both the presence and absence of the S9 mixture for the mutagenicity assay on TA98, TA100 and TA1535 strains of Salmonella typhimurium and Escherichia coli WP2 uvrA. The mixture consist of test substance $(0.1 \mathrm{~mL})$ and bacterial culture $(0.1 \mathrm{~mL})$ inoculated in $2.5 \%$ nutrient broth, incubated $16 \mathrm{~h}$ in a shaking incubator at $37^{\circ} \mathrm{C}, 200 \mathrm{rpm}$. S9 mixture (with metabolic activation)/phosphate buffer (without metabolic activation) were mixed with top agar and mixtures were vortexed, then poured on to the minimal glucose agar plates. Following incubation at $37^{\circ} \mathrm{C}$ for $48 \mathrm{~h}$, the revertant colonies were counted.

Cytotoxicity Assay The cytotoxic effects of the PhIP hydrochloride (Wako Pure Chemical Industries, Ltd., Osaka, Japan) and caffeic acid (Sigma, St. Louis, MO, U.S.A.) on Caco-2 cells were evaluated by the 3-(4,5-dimethylthiazol2-yl)-2,5-diphenyltetrazolium bromide (MTT) assay. Caco-2 cells were seeded in a density of $1 \times 10^{5}$ cells in 24 -well, and the medium was changed every other day. After $13 \mathrm{~d}$ postseeding, the medium was changed to serum free MEM. Cells were incubated for $24 \mathrm{~h}$, and the medium was removed. The well was replaced with transport medium (HBSS with $10 \mathrm{~mm} N-(2-$ hydroxyethyl)piperazine- $N^{\prime}$-(2-ethanesulfonic acid) (HEPES), $\mathrm{pH}$ 7.4), and incubated for $30 \mathrm{~min}$. PhIP hydrochloride was dissolved in dimethyl sulfoxide (DMSO) as a concentrated stock solution, and added to transport medium at $50 \mu \mathrm{m}$ final concentration containing $0.25 \%$ DMSO. Caffeic acid was made and stored as a stock solution. The diluted caffeic acid solution was made with addition of transport medium to the caffeic stock solution to have $0.5 \%$ DMSO before experimental use. After removing transport medium, transport medium containing samples were added, and cells were incubated for 3, 6, 12 and $24 \mathrm{~h}$. HBSS without samples incubated for $24 \mathrm{~h}$ was used as a control. After incubating the sample, MTT reagent was added, and treated with $20 \%$ sodium dodecyl sulfate (SDS) after $3 \mathrm{~h}$, followed by $16 \mathrm{~h}$-incubation at $37^{\circ} \mathrm{C}$. The conversion of the yellow MTT reagent to blue formazan crystals by hydrogenase in mitochondria was determined by measuring the absorbance at $540 \mathrm{~nm}$ using a spectrophotom- eter (V-530, Jasco Co., Ltd., Tokyo, Japan).

Measurement of Transepithelial Electrical Resistance Caco-2 cells (passages 23 to 28) were seeded onto a $12 \mathrm{~mm}$ transwell with pore diameter in $0.4 \mu \mathrm{m}$ of polycarbonate membrane insert and a growth area of $1.13 \mathrm{~cm}^{2}$ (Corning Incorporated, NY, U.S.A.) at a density of $1 \times 10^{5}$ cells $/ \mathrm{cm}^{2}$. Transepithelial electrical resistance (TEER) across the monolayer was measured to determine confluency and tight junction formation (EVOMX, World Precision Instruments). The medium was changed every other day, and the experiments were performed after $14 \mathrm{~d}$ post seeding once TEER values expressed over $1000 \Omega \cdot \mathrm{cm}^{2}$. During the transport experiment, the TEER of the Caco-2 cell monolayers was measured at $0,1,2$ and $3 \mathrm{~h}$.

Bidirectional Transport of PhIP Hydrochloride Prior to the permeability assay, the cell monolayer was washed with HBSS ( $\mathrm{pH}$ 7.4) to remove traces of culture media. After washing, the plates were incubated with transport medium (HBSS) for $30 \mathrm{~min}$ at $37^{\circ} \mathrm{C}$ in a $\mathrm{CO}_{2}$ incubator and the TEER value of the monolayer was measured. After the transport buffer was removed, for apical to basolateral transport studies, $500 \mu \mathrm{L}$ of PhIP hydrochloride (at $50 \mu \mathrm{M}$ final concentration in the presence of $0.25 \%$ DMSO) as well as caffeic acid (at $0.1,1,10$ and $100 \mu \mathrm{M}$ final concentration in the presence of $0.5 \%$ DMSO) in HBSS was added to the apical side and $1500 \mu \mathrm{L}$ of caffeic acid (at $0.1,1,10$ and $100 \mu \mathrm{M}$ final concentration in the presence of $0.5 \%$ DMSO) in HBSS was added to the basolateral side. Basolateral to apical transport studies were also carried out by adding PhIP hydrochloride solution to the basolateral compartment followed by measuring concentration in the apical compartment. For measuring the concentration of uptake and efflux of PhIP, samples were withdrawn from the basolateral $(1.5 \mathrm{~mL})$ and the apical $(0.5 \mathrm{~mL})$ compartment at $0,1,2$ and $3 \mathrm{~h}$. The apparent permeability coefficient, $P_{\text {app }}(\mathrm{cm} / \mathrm{s})$, for bidirectional transport studies was calculated according to the following Eq. 1:

$$
P_{\text {app }}=(\mathrm{d} Q / \mathrm{d} t) /\left(C_{0} \times A\right)
$$

where $\mathrm{d} Q / \mathrm{d} t$ is the cumulative transport rate (nmol/s) defined as the slope obtained by linear regression of cumulative transported amount as a function of time (s), $A$ is the surface area of inserts (1.12 $\mathrm{cm}^{2}$ in 12-wells), $C_{0}$ is the initial concentration of the PhIP hydrochloride on the donor side $(\mu \mathrm{M})$.

The concentration of the transported PhIP hydrochloride was measured from $P_{\text {app apical-to-basolteral }}\left(P_{\text {app } a b}\right)$ and $P_{\text {app basolateral-to-appical }}\left(P_{\text {app } b a}\right)$, respectively, and the efflux ratio (ER) was calculated from the following Eq. 2:

$$
\mathrm{ER}=P_{\text {app } b a} / P_{\text {app } a b}
$$

mRNA Expression of Efflux Transporters in Caco-2 Cell Caco-2 cells were cultured in six-well plates $\left(9.3 \mathrm{~cm}^{2}\right)$ for $14 \mathrm{~d}$ after reaching confluence, and subsequently treated with test compounds dissolved in HBSS. After incubation, the transport medium was removed, the cell monolayer was washed with ice-cold phosphate-buffered saline (PBS), and cells were harvested for RNA isolation. Total RNA was isolated using TRIzol reagent (Invitrogen, Eggenstein, Germany). The concentration of the RNA was determined by using a Nano Drop spectrophotometer (Nanodrop Technologies, Wilmington, DE, U.S.A.). Three micrograms of RNA were reverse transcribed 
using LeGene Express 1st Strand cDNA Synthesis System consisting of RnaUs Script RT and RNase inhibitor mix, cDNA Synthesis buffer, RNA annealing buffer OT and Nuclease-free water. The primer sequences for P-gp, MRP2, BCRP and GAPDH were as follows: P-gp (forward 5'-CTC ATC GTT TGT CTA CAG TTC GT-3', reverse 5'-GCT TTC TGT CTT GGG CTT GT-3'), MRP2 (forward 5'-GAC TAT GGG CTG ATA TCC AGT GT-3', reverse 5'-AGG CAC TCC AGA AAT GTG CT-3'), BCRP (forward 5'-TTT CAG CCG TGG AAC TCT TT-3', reverse 5'-TGA GTC CTG GGC AGA AGT TT-3'), GAPDH (forward 5'-AGG TCG GAG TCA ACG GAT TTG-3', reverse 5'-ACA GTC TTC TGG GTG GCA GTG-3'). PCR products were $288 \mathrm{bp}$ for P-gp, $490 \mathrm{bp}$ for MRP2, 517 bp for BCRP and 550 bp for GAPDH. Each $20 \mu \mathrm{L}$ amplification reaction mixture contained $2 \mu \mathrm{L}$ of $10 \times$ Taq buffer, $1.6 \mu \mathrm{L}$ of $2.5 \mathrm{~mm}$ dNTP, $0.2 \mu \mathrm{L}$ of G-Tag DNA polymerase, $0.8 \mu \mathrm{L}$ of each primer (Cosmo Genetech, Seoul, Korea) and DEPC water. Amplifications were performed using a MyCycler thermal cycler (Bio-Rad, Hercules, CA, U.S.A.). The thermal cycling began with an initial denaturation step at $94^{\circ} \mathrm{C}$ for $3 \mathrm{~min}$, followed by 27 cycles for MRP2 and glyceraldehyde3-phosphate dehydrogenase (GAPDH), 33 cycles for P-gp and 35 cycles for BCRP of denaturation at $94^{\circ} \mathrm{C}$ for $10 \mathrm{~s}$, annealing for P-gp, MRP2, BCRP and GAPDH at $65,61.8,63$ and $60^{\circ} \mathrm{C}$ for $30 \mathrm{~s}$, respectively, extension at $72^{\circ} \mathrm{C}$ for $20 \mathrm{~s}$, and final extension at $72^{\circ} \mathrm{C}$ for $5 \mathrm{~min}$. The mRNA amount of the genes of interest in each sample was normalized to its GAPDH content, and then referred to the negative control DMSO to obtain foldinductions.

Statistical Analysis Results are given as mean \pm S.D. Statistical analysis was performed using ANOVA, Tukey's test and Dunnett's multiple comparison test. A $p<0.05$ was considered significantly different from the control.

\section{RESULTS}

Relationship between Genotoxicity of PhIP and Caffeic Acid To investigate the genotoxicity of the PhIP and caffeic acid, a reverse mutation assay was performed using $S$. typhimurium TA98, TA100, TA1535 and E. coli WP2 uvrA strains, which require histidine and tryptophan, respectively, for growth. The number of colonies of S. typhimurium TA98, TA100, TA1535 and E. coli WP2 uvrA were not significantly increased, with or without metabolic activation with $50 \mu \mathrm{M}$ of PhIP treatment (Table 1). However, the number of colonies treated with $450 \mu \mathrm{M}$ PhIP, which showed positive mutagenic responses at a preliminary test, were significantly increased $(p<0.05)$ compared with those of negative control, with or without metabolic activation. On the other hand, a co-treatment of $450 \mu \mathrm{M}$ PhIP and $1 \mu \mathrm{M}$ caffeic acid did not decrease genotoxicity in $S$. typhimurium strains except TA100 strain without S9 mixture. However, the number of colonies co-treated with $450 \mu \mathrm{M} \mathrm{PhIP}$ and $10 \mu \mathrm{M}$ caffeic acid were significantly reduced $(p<0.05)$ compared to those with $450 \mu \mathrm{M}$ PhIP treatment alone on TA98, TA100, TA1535 strains, with or without S9 mixture. However, the colonies of E. coli WP2 uvrA strain were not decreased.

Cytotoxicity of PhIP and Caffeic Acid This effect of caffeic acid on genotoxicity of PhIP in Salmonella strains may be attributed to differential absorption of PhIP in cells. Next, we employed the human intestinal Caco-2 cell line as a model of the intestinal barrier, and evaluated the cytotoxic effects of PhIP.

Cell viability was measured using the MTT assay to evaluate the cytotoxicity of PhIP and caffeic acid on Caco-2 cells. Caco- 2 cells were exposed for $3 \mathrm{~h}$ to $50 \mu \mathrm{M} \mathrm{PhIP}$ and different concentrations of various caffeic acid, ranging from 0 to $100 \mu \mathrm{M}$. All data showed that the concentration of PhIP and caffeic acid $(0,0.1,1,10$ and $100 \mu \mathrm{M})$ used for $3 \mathrm{~h}$ were nontoxic to the cells (Fig. 1A). The cell viability at $50 \mu \mathrm{M} \mathrm{PhIP}$ and $10 \mu \mathrm{M}$ caffeic acid was determined in a time-dependent manner. Caco-2 cells cotreated with PhIP and caffeic acid showed a higher cell viability than those with PhIP for $24 \mathrm{~h}$ (Fig. 1B).

Changes in TEER of Caco-2 Cell Monolayers TEER was measured to determine the integrity of Caco-2 cell monolayers during the transport experiment. In apical-to-basolateral direction, after the $3 \mathrm{~h}$ incubation of PhIP and caffeic acid,

Table 1. Result of Bacterial Reverse Mutation Assay with PhIP and Caffeic Acid

\begin{tabular}{|c|c|c|c|c|c|c|}
\hline \multicolumn{2}{|c|}{ Compound } & \multirow{3}{*}{ S9 mixture } & \multicolumn{4}{|c|}{ Mean revertants per plate \pm S.D. } \\
\hline \multirow{2}{*}{ PhIP ( $\mu \mathrm{M} /$ plate $)$} & \multirow{2}{*}{ Caffeic acid ( $\mu \mathrm{M} /$ plate $)$} & & \multicolumn{3}{|c|}{ Salmonella typhimurium } & \multirow{2}{*}{ E. coli WP2 uvrA } \\
\hline & & & TA 98 & TA 100 & TA 1535 & \\
\hline- & - & - & $30 \pm 6$ & $57 \pm 3$ & $43 \pm 3$ & $23 \pm 2$ \\
\hline \multirow[t]{3}{*}{50} & - & - & $29 \pm 2$ & $55 \pm 3$ & $46 \pm 5$ & $24 \pm 3$ \\
\hline & 1 & - & $28 \pm 4$ & $57 \pm 4$ & $47 \pm 3$ & $26 \pm 5$ \\
\hline & 10 & - & $28 \pm 3$ & $55 \pm 14$ & $47 \pm 5$ & $22 \pm 4$ \\
\hline \multirow[t]{3}{*}{450} & - & - & $89 \pm 8$ & $137 \pm 8$ & $103 \pm 8$ & $47 \pm 3$ \\
\hline & 1 & - & $80 \pm 8$ & $117 \pm 8^{a)}$ & $97 \pm 5$ & $48 \pm 3$ \\
\hline & 10 & - & $63 \pm 5^{a)}$ & $97 \pm 5^{a)}$ & $\left.89 \pm 7^{a}\right)$ & $45 \pm 3$ \\
\hline - & - & + & $33 \pm 5$ & $52 \pm 4$ & $46 \pm 4$ & $26 \pm 3$ \\
\hline \multirow[t]{3}{*}{50} & - & + & $27 \pm 8$ & $58 \pm 6$ & $46 \pm 4$ & $28 \pm 4$ \\
\hline & 1 & + & $25 \pm 5$ & $52 \pm 9$ & $42 \pm 3$ & $28 \pm 4$ \\
\hline & 10 & + & $29 \pm 4$ & $47 \pm 5$ & $47 \pm 3$ & $27 \pm 6$ \\
\hline \multirow[t]{3}{*}{450} & - & + & $89 \pm 4$ & $121 \pm 10$ & $98 \pm 3$ & $46 \pm 3$ \\
\hline & 1 & + & $87 \pm 7$ & $113 \pm 6$ & $96 \pm 4$ & $47 \pm 4$ \\
\hline & 10 & + & $71 \pm 9^{a)}$ & $83 \pm 6^{a)}$ & $92 \pm 3^{a)}$ & $44 \pm 6$ \\
\hline
\end{tabular}

a) Inhibition growth. 

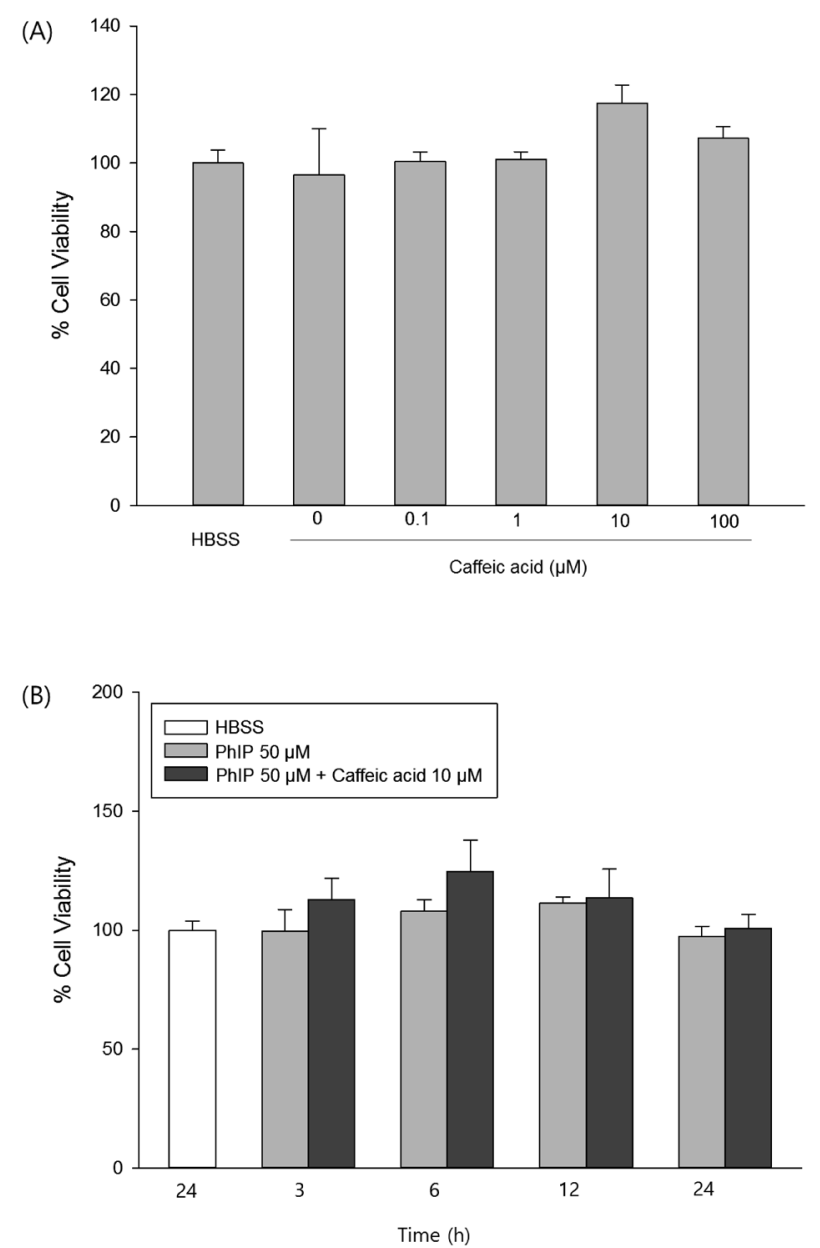

Fig. 1. Cell Viability of $50 \mu \mathrm{M}$ PhIP and Caffeic Acid (0, 0.1, 1, 10, $100 \mu \mathrm{m})$ in Caco-2 Cells with Different Incubation Periods

$50 \mu \mathrm{M}$ PhIP and caffeic acid $(0,0.1,1,10$ and $100 \mu \mathrm{M})$ used for $3 \mathrm{~h}$ were non-toxic to the cells (Fig. 1A). The cell viability at $50 \mu \mathrm{M}$ PhIP and $10 \mu \mathrm{M}$ caffeic acid was determined in a time-dependent manner. The beginning $24 \mathrm{~h}$ did not have any effect on Caco-2 cells (Fig. 1B). HBSS without samples for $24 \mathrm{~h}$ incubation was used as a control. Results are expressed in percent of control obtained with transport medium and given as mean and standard deviation with $n=3$.

TEER was reduced to $65-75 \%$ of the original value in $0 \mathrm{~h}$ (Fig. 2A). In basolateral-to-apical direction, TEER of Caco-2 cells was reduced to $75-82 \%$ (Fig. 2B). The reduction in TEER indicated that PhIP and caffeic acid may affect the paracellular route through the opening of a tight junction, and thus reducing the cell integrity of Caco-2 cells. However, TEER values were maintained over $500 \Omega \cdot \mathrm{cm}^{2}$, and there is no significant difference between groups treated with $\mathrm{PhIP}$ and different concentrations of caffeic acid.

Effect of Caffeic Acid on the Transport of PhIP across Caco-2 Cells The effect of increasing concentrations of caffeic acid on the transport of PhIP in both directions was presented in Fig. 3. The mean $P_{\text {app }}$ values were calculated from cumulative amount of PhIP for both sides. The $P_{\text {app } a b}$ of PhIP in the presence of $10 \mu \mathrm{M}$ caffeic acid $\left(14.7 \times 10^{-6} \pm 0.1 \times 10^{-6}\right.$ $\mathrm{cm} / \mathrm{s}$ ) was 1.2 -fold lower than that of PhIP in the absence of caffeic acid $\left(17.7 \times 10^{-6} \pm 0.6 \times 10^{-6} \mathrm{~cm} / \mathrm{s}\right)$ (Fig. 3A). However, the $P_{\text {app } a b}$ of PhIP in the presence of $100 \mu \mathrm{M}$ caffeic acid $\left(18.3 \times 10^{-6} \pm 0.4 \times 10^{-6} \mathrm{~cm} / \mathrm{s}\right)$ was 1.1 -fold higher than that of $\mathrm{PhIP}$ in the absence of caffeic acid. These results are in accordance with the $P_{\text {app ba }}$ of PhIP in the opposite direction, from the basolateral to the apical compartment. $P_{\mathrm{app} b a}$ of $\mathrm{PhIP}$
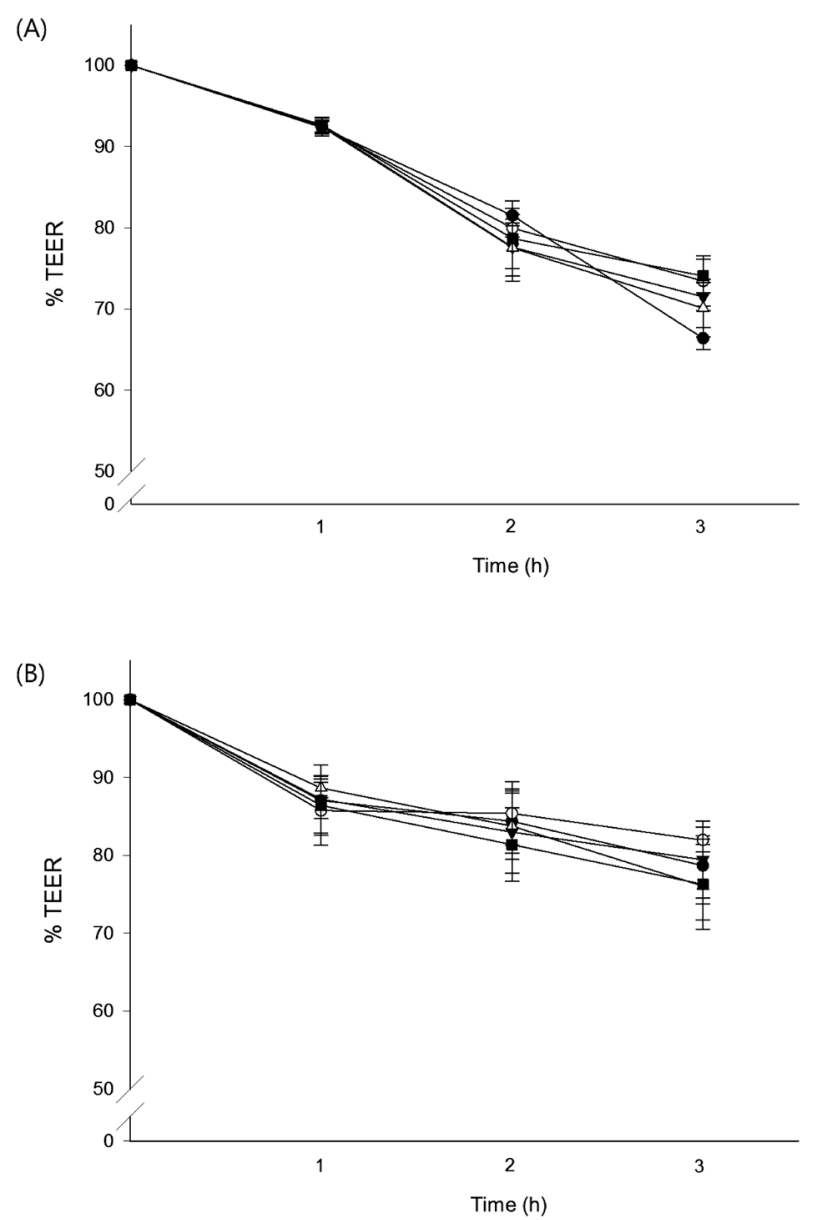

Fig. 2. Transepithelial Electrical Resistance (TEER) of Caco-2 Cell Monolayers Plotted against Time of Incubation after Treatment of $50 \mu \mathrm{M}$ $\mathrm{PhIP}$ and Different Concentrations of Caffeic Acid

○, $0 \mu \mathrm{m} ; \bigcirc, 0.1 \mu \mathrm{m} ; \nabla, 1 \mu \mathrm{m} ; \Delta, 10 \mu \mathrm{m} ; \mathbf{\square}, 100 \mu \mathrm{m}$. The TEER was measured in both apical-to-basolateral (Fig. 2A) and basolateral-to-apical (Fig. 2B) direction. Each point indicates the means \pm S.D. $(n \geq 3)$.

in the presence of $10 \mu \mathrm{M}$ caffeic acid $\left(7.1 \times 10^{-6} \pm 1.4 \times 10^{-6} \mathrm{~cm} / \mathrm{s}\right)$ is the highest among the groups. An increase in the $P_{\text {app } b a}$ from $3.7 \times 10^{-6} \mathrm{~cm} / \mathrm{s}$ for the control to $7.1 \times 10^{-6} \mathrm{~cm} / \mathrm{s}$ in the presence of $10 \mu \mathrm{M}$ caffeic acid was observed. However, the $P_{\text {app } b a}$ of PhIP in the presence of $100 \mu \mathrm{M}$ caffeic acid $\left(2.7 \times 10^{-6} \pm 1.3 \times 10^{-6} \mathrm{~cm} / \mathrm{s}\right)$ was decreased.

Together these changes result in an increase in the $P_{\text {app } b a} / P_{\text {app } a b}$ ratio for PhIP in the presence of $10 \mu \mathrm{M}$ caffeic acid. The ratio $P_{\text {app } b a} / P_{\text {app } a b}$ showed a concentration-dependent increase from a value of 0.2 for Caco- 2 monolayers exposed to $50 \mu \mathrm{M} \mathrm{PhIP}$ in the absence of caffeic acid to a value of 0.5 for Caco-2 monolayers exposed to $50 \mu \mathrm{M}$ PhIP in the presence of $10 \mu \mathrm{M}$ caffeic acid (Fig. 3B). However, a decrease in the $P_{\text {app } b a} / P_{\text {app } a b}$ value of 0.2 in the presence of $100 \mu \mathrm{M}$ caffeic acid was also observed.

Effect of Caffeic Acid on the Transport of PhIP Mediated by P-gp, MRP-2 and BCRP Mediated Transport of PhIP Treatment of the intestinal Caco-2 cells with PhIP or caffeic acid resulted in a time-dependent induction of efflux transporter mRNA expression (Fig. 4). PhIP induced mRNAs of efflux trasporters in the presence of caffeic acid, compared with PhIP only. Treatment with $50 \mu \mathrm{M}$ PhIP and $10 \mu \mathrm{M}$ caffeic acid for $3 \mathrm{~h}$ resulted in an enhanced mRNA expression of P-gp and BCRP by a factor of 2.5 and 1.8, respectively (Figs. 

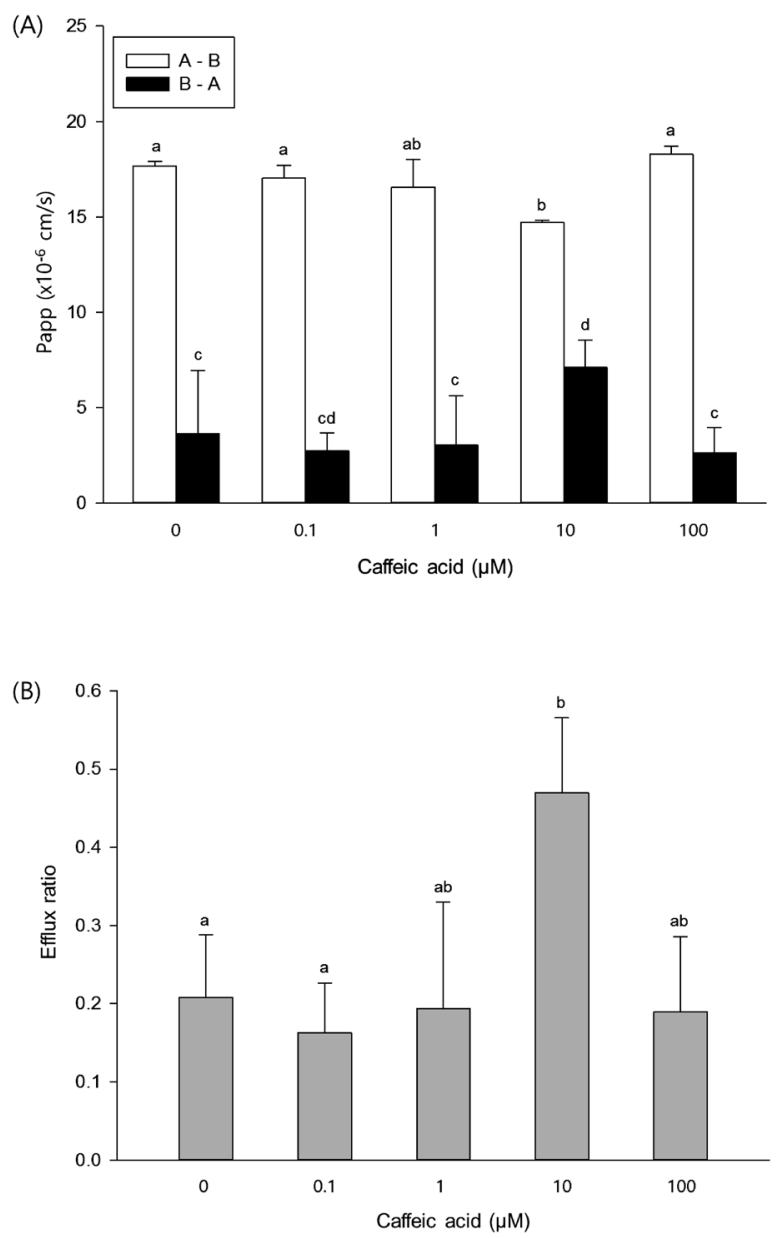

Fig. 3. (A) Apparent Permeability Coefficient of Bidirectional PhIP Transport across Caco-2 Cell Monolayers for $50 \mu \mathrm{M} \mathrm{PhIP}$ in the Presence of Different Concentrations of Caffeic Acid; (B) Efflux Ratios $\left(P_{\text {app } b a} / P_{\text {app } a b}\right)$ of Caco-2 Monolayers Exposed to $50 \mu \mathrm{M}$ PhIP and Different Concentrations of Caffeic Acid

PhIP was loaded in the apical compartment, different concentrations caffeic acid was loaded on both sides. The apparent permeability coefficient $\left(P_{\text {app }}\right)$ in the apicalto-basolateral direction (white bars) is the lowest in the presence of $10 \mu \mathrm{m}$ caffeic acid, while the $P_{\text {app }}$ in the basolateral-to-apical direction (black bars) is the highest. Values are means \pm S.D. $(n=3)$. Bars with different superscripts are significantly different at $p<0.05$ by Tukey's test and Dunnett's multiple comparison test. Each bar indicates mean \pm S.D. $(n=3)$.

$4 \mathrm{~A}$ and $\mathrm{B})$. The highest induction of P-gp and BCRP was observed after $3 \mathrm{~h}$, however after $6 \mathrm{~h}$, the induction potency declined again. In contrast, $50 \mu \mathrm{M}$ PhIP or PhIP with $10 \mu \mathrm{M}$ caffeic acid only slightly induced the MRP2 mRNA expression (Fig. 4C). Gene expression of MRP2 was not significantly affected by the cotreatment with $50 \mu \mathrm{M}$ PhIP and $10 \mu \mathrm{M}$ caffeic acid.

\section{DISCUSSION}

P-gp, MRP2 and BCRP in the apical membrane are expressed, and are responsible for the most pharmacologically relevant $\mathrm{ABC}$ transporters. ${ }^{21)}$ These transporters are located within the polarized apical membrane of the instestine, liver and kidney, and involved in modulation, limiting entry of xenobiotics. We investigated the bidirectional transport of PhIP, a cooked-food mutagen in the presence of caffeic acid using the Caco-2 cell monolayer, which is a well-established model of human intestinal absorption, ${ }^{16)}$ and measured the cumula-
(A)
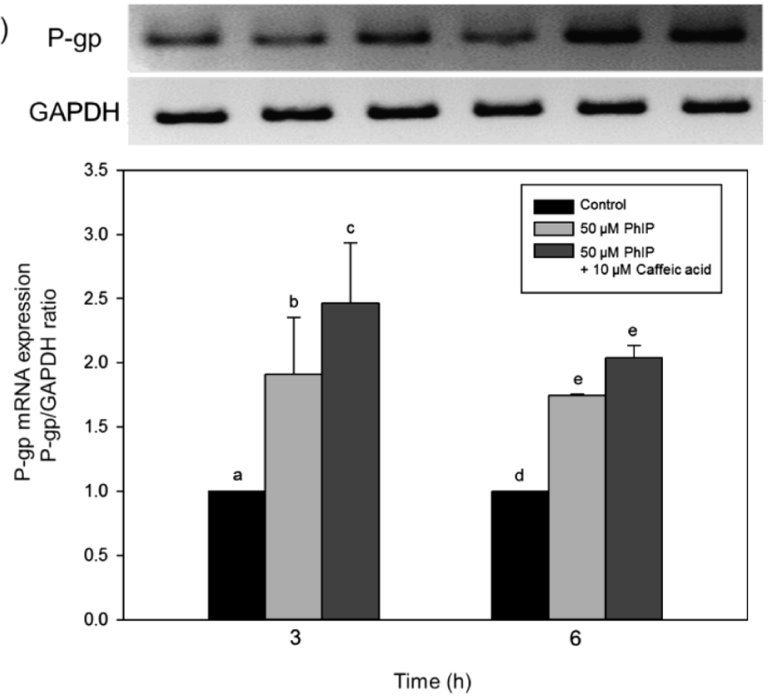

(B)
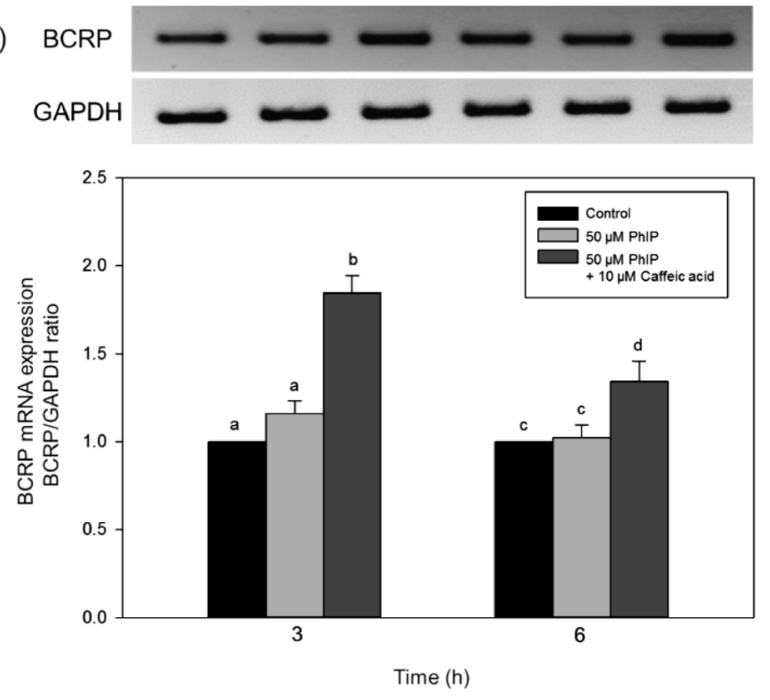

(C)
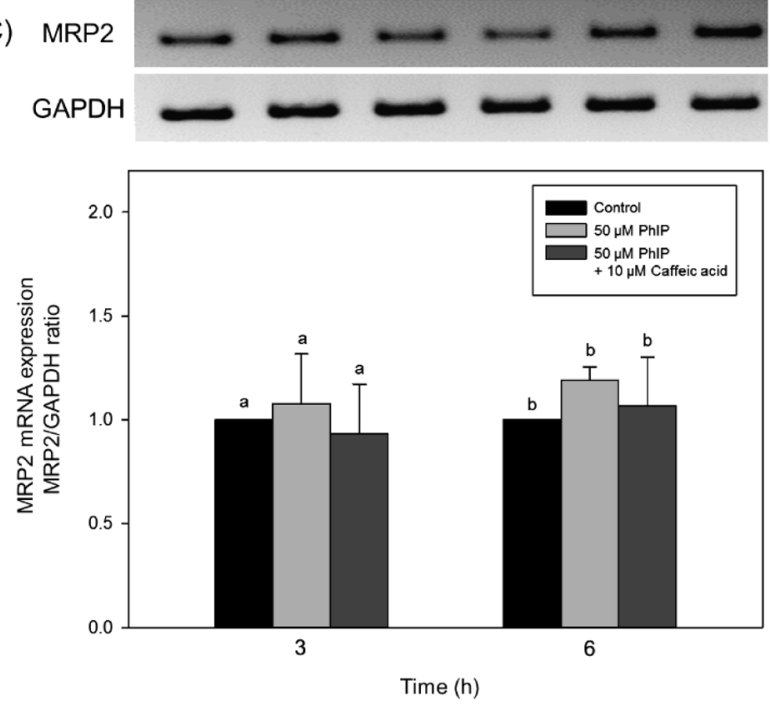

Fig. 4. Caffeic Acid Enhanced mRNA Expression of P-gp (A), BCRP (B), MRP2 (C) in Caco-2 Cell Monolayers

mRNA expression was determined by reverse transcription PCR, and the results are expressed as mean \pm S.D. $(n=3)$. Bars with different superscripts are significantly different at $p<0.05$ by Tukey's test and Dunnett's multiple comparison test. 
tive amount and apparent permeability coefficients $\left(P_{\text {app }}\right)$ in both directions. In the previous study, different flavonoids enhanced the absorption of PhIP by acting as inhibitors of MRPs and BCRP at micro molar levels (5.6-37.3 $\mu \mathrm{M})$ present in the regular Western diet. ${ }^{22}$ However, individual flavonoid can have different effect on modulation of an ABC transporter, MRP1. ${ }^{23)}$ In our study suggests that $10 \mu \mathrm{M}$ caffeic acid increases the efflux of PhIP. Hydroxycinnamic acid conjugates also influence the selected ABC transport activity such as MRP2 and BCRP, and at low concentration (below $10 \mu \mathrm{M}$ ) show no effect on the MRP2 and BCRP activity. ${ }^{20)}$ However, at a high concentration of hydroxycinnamic acid conjugates slightly interact with MRP2 and BCRP.

The mRNA levels of efflux ABC transporter may explain the transport of the PhIP in the presence of caffeic acid. The gene of drug metabolizing enzyme was induced by polyphenols which can enhance the detoxification pathways by stimulating expression of Phase II enzymes and Phase III transporters including P-gp and multidrug resistance proteins. Phase III transporters, P-gp and MRP2 can be induced through activation of orphan nuclear receptors pregnane $\mathrm{X}$ receptor (PXR), which also control the expression of Phase I and Phase II enzymes. ${ }^{24)}$ On the other hand, BCRP expression is only minimally affected by PXR or constitutive androstane receptor (CAR) activators. Instead, in response to chemical ligands, aryl hydrocarbon receptor (AhR) enhances the expression of $\mathrm{BCRP}^{25)}$. Although a weak effect of 2,3,7,8-tetrachlorodibenzo- $p$-dioxin (TCDD)-stimulated CYP1A1 in the presence of caffeic acid, the direct interaction for activation of AhR by caffeic acid in T47D breast cancer cells was reported. ${ }^{26)}$ Thus, caffeic acid may modulate interplay between AhR and CAR/PXR contributing further to the coordinated PhIP-detoxification. On the other hand, it was reported that caffeic acid related phenolic acids including $p$-coumaric acid, ferulic acid, gallic acid and gentisic acid increased hepatic MRP3 mRNA levels but left MRP2 mRNA levels unchanged. ${ }^{27)}$ This finding may explain our results that caffeic acid induced the mRNA levels of P-gp and BCRP except for MRP2. These mechanisms can explain how caffeic acid increase mRNA levels of efflux transporters in related with the decrease in the transport of PhIP.

In conclusion, our study showed that caffeic acid present in a physiological concentration range increased the efflux of the PhIP transport by up-regulating efflux transporters. Therefore, caffeic acid may be used as not only an antioxidant, but also an inhibitor of the absorption of food borne carcinogen, PhIP. However, further studies, especially in vivo studies, are required to confirm these results.

Acknowledgments This research was supported by High Value-Added Food Technology Development Program (111021-03-HD110) for Korea Institute of Planning and Evaluation for Technology in Food, Agriculture, Forestry and Fisheries (iPET). This research was supported by a Korea University Grant. The authors thank the Korea University-CJ Food Safety Center for providing the equipment and facilities.

Conflict of Interest The authors declare no conflict of interest.

\section{REFERENCES}

1) Jägerstad M, Skog K, Grivas S, Olsson K. Formation of heterocyclic amines using model systems. Mutation Research/Genetic Toxicology, 259, 219-233 (1991).

2) Gooderham NJ, Murray S, Lynch A, Edwards R, Yadollahi-Farsani M, Bratt C, Rich K, Zhao K, Murray B, Bhadresa S, Crosbie SJ, Boobis AR, Davies DS. Heterocyclic amines: evaluation of their role in diet associated human cancer. Br. J. Clin. Pharmacol., 42, 91-98 (1996).

3) Manabe S, Tohyama K, Wada O, Aramaki T. Detection of a carcinogen, 2-amino-1-methyl-6-phenylimidazo[4,5-b]pyridine (PhIP), in cigarette smoke condensate. Carcinogenesis, 12, 1945-1947 (1991).

4) Manabe S, Kurihara N, Wada O, Izumikawa S, Asakuno K, Morita M. Detection of a carcinogen, 2-amino-1-methyl6-phenylimidazo[4,5-b]pyridine, in airborne particles and dieselexhaust particles. Environ. Pollut., 80, 281-286 (1993).

5) Edwards RJ, Murray BP, Murray S, Schulz T, Neubert D, Gant TW, Thorgeirsson SS, Boobis AR, Davies DS. Contribution of CYP1A1 and CYP1A2 to the activation of heterocyclic amines in monkeys and human. Carcinogenesis, 15, 829-836 (1994).

6) Turesky RJ, Lang NP, Butler MA, Teitel CH, Kadlubar FF. Metabolic activation of carcinogenic heterocyclic aromatic amines by human liver and colon. Carcinogenesis, 12, 1839-1845 (1991).

7) Hatch FT, Lightstone F, Colvin M. Quantitative structure-activity relationship of flavonoids for inhibition of heterocyclic amine mutagenicity. Environ. Mol. Mutagen., 35, 279-299 (2000).

8) Coles BF, Kadlubar FF. Detoxification of electrophilic compounds by glutathione $S$-transferase catalysis: Determinants of individual response to chemical carcinogens and chemotherapeutic drugs? Biofactors, 17, 115-130 (2003).

9) Choudhary S, Sood S, Donnell RL, Wang HCR. Intervention of human breast cell carcinogenesis chronically induced by 2-amino1-methyl-6-phenylimidazo[4,5-b]pyridine. Carcinogenesis, 33, 876885 (2012).

10) Wang R, Dashwood WM, Nian H, Löhr CV, Fischer KA, Tsuchiya $\mathrm{N}$, Nakagama H, Ashktorab H, Dashwood RH. NADPH oxidase overexpression in human colon cancers and rat colon tumors induced by 2-amino-1-methyl-6-phenylimidazo[4,5-b]pyridine (PhIP). Int. J. Cancer, 128, 2581-2590 (2011).

11) Sinha R, Park Y, Graubard BI, Leitzmann MF, Hollenbeck A, Schatzkin A, Cross AJ. Meat and meat-related compounds and risk of prostate cancer in a large prospective cohort study in the United States. Am. J. Epidemiol., 170, 1165-1177 (2009).

12) Schinkel AH, Jonker JW. Mammalian drug efflux transporters of the ATP binding cassette (ABC) family: an overview. Adv. Drug Deliv. Rev., 55, 3-29 (2003).

13) Marquez B, Van Bambeke F. ABC multidrug transporters: Target for modulation of drug pharmacokinetics and drug-drug interactions. Curr. Drug Targets, 12, 600-620 (2011).

14) Dietrich CG, De Waart DR, Ottenhoff R, Bootsma AH, Van Gennip $\mathrm{AH}$, Elferink RPJO. Mrp2-deficiency in the rat impairs biliary and intestinal excretion and influences metabolism and disposition of the food-derived carcinogen 2-amino-1-methyl-6-phenylimidazo[4,5-b]pyridine (PhIP). Carcinogenesis, 22, 805-811 (2001).

15) Myllynen P, Kummu M, Kangas T, Ilves M, Immonen E, Rysä J, Pirilä R, Lastumäki A, Vähäkangas KH. ABCG2/BCRP decreases the transfer of a food-born chemical carcinogen, 2-amino-1-methyl6-phenylimidazo[4,5-b]pyridine (PhIP) in perfused term human placenta. Toxicol. Appl. Pharmacol., 232, 210-217 (2008).

16) Walle UK, Walle T. Transport of the cooked-food mutagen 2-amino-1-methyl-6-phenylimidazo[4,5-b]pyridine (PhIP) across the human intestinal Caco-2 cell monolayer: role of efflux pumps. Carcinogenesis, 20, 2153-2157 (1999).

17) Yang SY, Hong C, Lee H, Park S, Park B, Lee KW. Protective 
effect of extracts of Perilla frutescens treated with sucrose on tertbutyl hydroperoxide-induced oxidative hepatotoxicity in vitro and in vivo. Food Chem., 133, 337-343 (2012).

18) Yang SY, Hong CO, Lee GP, Kim CT, Lee KW. The hepatoprotection of caffeic acid and rosmarinic acid, major compounds of Perilla frutescens, against $t$-BHP-induced oxidative liver damage. Food Chem. Toxicol., 55, 92-99 (2013).

19) Konishi Y, Kobayashi S. Transepithelial transport of chlorogenic acid, caffeic acid, and their colonic metabolites in intestinal Caco-2 cell monolayers. J. Agric. Food Chem., 52, 2518-2526 (2004).

20) Wong CC, Barron D, Orfila C, Dionisi F, Krajcsi P, Williamson G. Interaction of hydroxycinnamic acids and their conjugates with organic anion transporters and ATP-binding cassette transporters. Mol. Nutr. Food Res., 55, 979-988 (2011).

21) Alvarez AI, Real R, Pérez M, Mendoza G, Prieto JG, Merino G. Modulation of the activity of $\mathrm{ABC}$ transporters (P-glycoprotein, MRP2, BCRP) by flavonoids and drug response. J. Pharm. Sci., 99, 598-617 (2010)

22) Schutte ME, Freidig AP, van de Sandt JJV, Alink GM, Rietjens IMCM, Groten JP. An in vitro and in silico study on the flavonoid mediated modulation of the transport of 2-amino-1-methyl- 6-phenylimidazo[4,5-b]pyridine (PhIP) through Caco-2 monolayers. Chem. Biol. Interact., 217, 204-215 (2006).

23) Leslie EM, Mao QC, Oleschuk CJ, Deeley RG, Cole SPC. Modulation of multidrug resistance protein 1 (MRP1/ABCC1) transport and ATPase activities by interaction with dietary flavonoids. Mol. Pharmacol., 59, 1171-1180 (2001).

24) Galli F. Interactions of polyphenolic compounds with drug disposition and metabolism. Curr. Drug Metab., 8, 830-838 (2007).

25) Tolson $\mathrm{AH}$, Wang $\mathrm{H}$. Regulation of drug-metabolizing enzymes by xenobiotic receptors: PXR and CAR. Adv. Drug Deliv. Rev., 62, 1238-1249 (2010).

26) Kampa M, Alexaki VI, Notas G, Nifli AP, Nistikaki A, Hatzoglou A, Bakogeorgou E, Kouimtzoglou E, Blekas G, Boskou D, Gravanis A, Castanas E. Antiproliferative and apoptotic effects of selective phenolic acids on T47D human breast cancer cells: potential mechanisms of action. Breast Cancer Res., 6, R63-R74 (2004).

27) Yeh CT, Yen GC. Introduction of hepatic antioxidant enzymes by phenolic acids in rats is accompanied by increased levels of multidrug registance-associated protein 3 mRNA expresseion. J. Nutr., 136, 11-15 (2006). 